\title{
Budesonide increased symptom free days in patients with recent onset mild asthma at an additional cost of US $\$ 0.42 /$ day
}

Sullivan SD, Buxton M, Andersson LF, et al. Cost-effectiveness analysis of early intervention with budesonide in mild persistent asthma. J Allergy Clin Immunol 2003;1 12:1229-36.

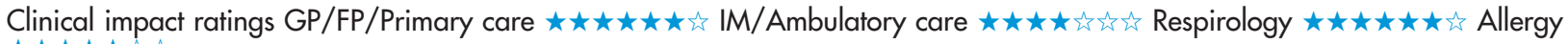

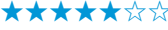

In patients with recent onset mild asthma, what is the incremental cost effectiveness of early intervention with budesonide compared with usual care?

\section{METHODS}

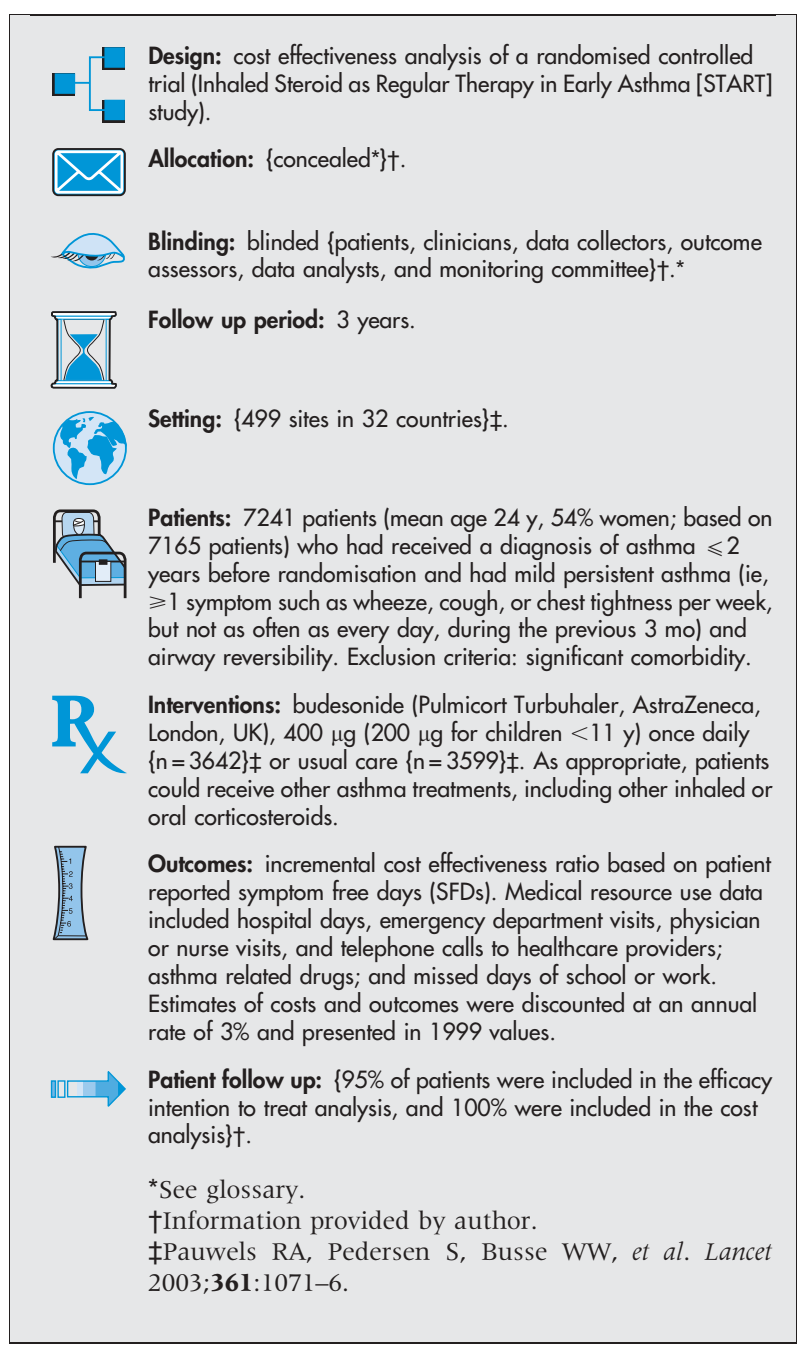

\section{MAIN RESULTS}

At the end of 3 years, patients in the budesonide group had a mean of 14.1 more SFDs/year than patients who received usual care. From a healthcare payer perspective, the additional cost in the budesonide group was US $\$ 0.42 /$ day; the incremental cost effectiveness ratio was

For correspondene: DrSD Sullivan, University of Washington, Seatle, WA, USA. sdsull@u.washington.edu

Source of funding: AstraZeneca Research and Development.
US $\$ 11.30$ per SFD/year gained (95\% CI $\$ 8.60$ to $\$ 14.90)$. From a societal perspective, which included the costs of absences from work or school, the additional cost in the budesonide group was US\$0.14/ day; the incremental cost effectiveness ratio was US $\$ 3.70$ per SFD/ year gained (CI $\$ 0.10$ to $\$ 8.00$ ).

\section{CONCLUSIONS}

In patients with recent onset mild asthma, budesonide increased the number of symptom free days compared with usual care. From a healthcare payer perspective, the net cost of budesonide use was an additional US $\$ 0.42 /$ day, whereas from a societal perspective, the additional cost was US\$0.14/day.

\section{Commentary}

Come studies show that patients with asthma who are started on inhaled corticosteroids (ICSs) early might benefit more than those started later. ${ }^{1}$ Other studies have reported that the addition of ICSs in steroid dependent patients reduces costs ${ }^{2}$ and improves cost effectiveness in patients with moderate-to-severe asthma. ${ }^{3}$ Little is known about the cost effectiveness of ICSs in patients with mild asthma.

Sullivan et al evaluate the cost effectiveness of early intervention with budesonide in mild persistent asthma. Study strengths include the large sample, length of follow up, and a design that reflects a real world approach to patient care. The fact that steroids could be added during the study (31\% of treatment and $45 \%$ of control group patients) means that the effects of ICSs were underestimated. Weaknesses include the high number of patients who did not complete the 3 year follow up (approximately $25 \%$, although only $5 \%$ were not included in the analysis), which likely reflects the difficulties of patient compliance in mild disease.

Interestingly, the mean number of SFDs gained per year was 5.6 for children and 20.0 for adults, although early intervention was more cost effective in the youngest age group. This relates to the lower cost of medication in children because of lower dosages. Although a societal cost of 14 cents/day appears to be a bargain for improving quality of life of patients with mild asthma, the data can be viewed from many perspectives. The cost to healthcare payers to prevent 1 severe exacerbation number needed to treat $[N N T]=76\}^{*}$ is about $\left\{\$ 11600 /\right.$ year $^{*}$, and the cost to prevent a life threatening episode $\{N N T=572\}^{*}$ is about $\{\$ 87600 / \text { year }\}^{*}$. Nevertheless, this well done study emphasises that even low dose ICSs (1 puff/d of budesonide) can significantly improve asthma control and reduce severe exacerbations.

*Data provided by author.

Jay Peters, MD University of Texas Health Science Center San Antonio, Texas, USA

1 Selroos $O$, Pietinalho $A$, Löfroos $A B$, et al. Effect of early vs late intervention with inhaled corticosteroids in asthma. Chest 1995; 108:1228-34.

2 Adelroth E, Thompson S. Advantages of high-dose inhaled budesonide [lefter]. Lancet 1988;1:476.

3 Rutten-van Mölken MP, Van Doorslaer EK, Jansen MC, et al. Costs and effects of inhaled corticosteroids and bronchodilators in asthma and chronic obstructive pulmonary disease. Am J Respir Crit Care Med 1995;151:97582. 